\title{
Early Effects of Hemodialysis on Pulmonary Function in Patients with End-Stage Renal Disease
}

\author{
Mohammad Kazem Momeni ${ }^{1{ }^{1},}$, Elham Shahraki ${ }^{1, " *}$, Farhad Yarmohammadi ${ }^{1}$, Ali Alidadi ${ }^{1}$ and Narjes \\ Sargolzaie $^{2}$ \\ 'Zahedan University of Medical Sciences, Ali Ibne Abitaleb Hospital, Zahedan, Iran \\ ${ }^{2}$ Health Promotion Research Center, Zahedan University of Medical Sciences, Zahedan, Iran \\ "Corresponding author: Zahedan University of Medical Sciences, Ali Ibne Abitaleb Hospital, Zahedan, Iran. Tel: +989153403147, Email: drkazemmomeni@gmail.com \\ "Corresponding author: Zahedan University of Medical Sciences, Ali Ibne Abitaleb Hospital, Zahedan, Iran. Tel: +989155418372, Email: shahrekie@gmail.com \\ Received 2019 July 30; Revised 2019 September 11; Accepted 2019 October 05.
}

\begin{abstract}
Background: Renal failure may directly or indirectly influence pulmonary ventilation. Since hemodialysis can decrease the extra liquids, improvement in pulmonary function by decreasing liquids in the lungs is expected.

Objectives: This study aimed to assess the effects of acute hemodialysis on spirometry parameters.

Methods: A cross-sectional study was conducted among patients with end-stage renal disease who referred for hemodialysis to Ali Ibn Abitaleb Hospital of Zahedan City during 2016. Patient data including age, gender, and body mass index (BMI) were collected. Spirometry was performed one hour before and after hemodialysis, and spirometry parameters including vital capacity (VC), forced vital capacity (FVC), forced expiratory volume in the first second (FEV1), FEV1/FVC, peak expiratory flow (PEF), forced expiratory flow between $25 \%$ and $75 \%$ FVC (FEF $25 \%$ - 75\%) were measured.

Results: A total number of 50 patients (30 men) completed spirometry. In men, there were a significant increase in FEV1 (mean difference $=0.217 ; \mathrm{P}=0.003)$ and FVC $(0.298 ; \mathrm{P}=0.027)$ and a significant decrease in FEV1/FVC $(-4.153 ; \mathrm{P}=0.038)$ after hemodialysis. In women, there was no significant change in the means of spirometry parameters. In addition, no significant relationship was found between PFT changes and BMI, weight change, or ultrafiltration volume.

Conclusions: Our results showed that hemodialysis may improve pulmonary function tests in men. Studies with larger cohorts of patients are needed to derive valid effect estimates of hemodialysis on spirometry parameters with considering the role of chronic kidney diseases, various underlying diseases, different hemodialysis methods, and other related confounders.
\end{abstract}

Keywords: End-Stage Renal Disease, Hemodialysis, Pulmonary Function Test, Spirometry

\section{Background}

Renal disease and renal failure are two leading causes of the global burden of diseases and important causes of death in developing countries. Chronic kidney disease (CKD) is considered one of the main global health issues due to its high prevalence, progression to end-stage renal disease (ESRD), and early death (1-4). CKD emanates from various renal damages and is an irreversible, progressive disease that may progress gradually and lead to the loss of renal function and ESRD (5). The accumulation of toxins, liquids, and electrolytes due to the decreased glomerular filtration will lead to the uremic syndrome or patient's death if it is not treated effectively with renal replacement therapies such as hemodialysis, peritoneal dialysis, or kidney transplantation (6). In spite of increased life expectancy due to dialysis technologies, patients' problems, especially those related to systemic or metabolic complications and hemodialysis complications, have increasingly grown $(5,7,8)$. The lungs' mechanical function and ventilation are associated with the kidneys' function in normal and disease conditions (9).

Pulmonary complications are common in patients with advanced chronic kidney disease.

Pulmonary disorders like pulmonary edema, pleural effusion, acute respiratory distress syndrome, increased pulmonary capillary permeability, pulmonary fibrosis, pulmonary calcification, pulmonary hypertension, hemosiderosis, pleural fibrosis, obstructive apnea, muscle myopathy, and low respiratory muscle strength are observed among these patients (10-13). They might be directly due to uremic toxins or indirectly because of anemia, immune suppression, extra calcification, malnutrition, electrolyte disorders, acid-base imbalance, and volume over- 
load (9,14-19). On the other hand, ESRD can influence pulmonary ventilation or function directly or indirectly (20).

ESRD is an inflammatory state. Although hemodialysis decreases the fluid overload and improves pulmonary function, the inflammation can affect the respiratory system and mortality rate (13). Few studies have examined the changes in pulmonary function among patients with ESRD treated with hemodialysis and have reported controversial results (11).

\section{Objectives}

After the Rahgoshai's study, which was conducted in 2010 on 26 patients, we decided to conduct this study in Zahedan to examine the effects of acute hemodialysis on spirometry parameters.

\section{Methods}

This was a cross-sectional study conducted among ESRD patients who referred to Ali Ibn Abitaleb Hospital for hemodialysis in Zahedan, Southeast of Iran, in 2016. The Research Ethics Committee of Zahedan University of Medical Sciences approved the study protocol (code of ethics: IR.ZAUMS.REC.1395.288). Informed consent was obtained from all the patients at the time of study enrollment.

The inclusion criteria included patients with ESRD, age above 18 years, records of hemodialysis three times a week at least for three months, KT/V $>1.2$, ability to perform PFT, and being hemodynamically stable. The exclusion criteria were being a smoker (currently or recently), having pulmonary diseases such as acute pulmonary infection, asthma, chronic obstructive pulmonary disease, tuberculosis, cardiovascular diseases, neuromuscular disorders, history of chest or abdominal surgery, pulmonary distress, and diuretic users.

Hemodialysis was done using Dialog + B-Braun dialysis machines (Melsungen, Germany) that lasted four hours each time. The blood flow rate varied from 300 to $350 \mathrm{~mL} / \mathrm{min}$ and the dialysate flow was constant at 500 $\mathrm{mL} / \mathrm{min}$. The dialyzer membrane was low-flux biocompatible, and bicarbonate buffer was used. The ultrafiltration rate was based on the patients' conditions and their weight gain during the interdialytic period. Blood pressure was stable before and after hemodialysis.

Patients' data including age, gender, and body mass index (BMI) were recorded and spirometry was done one hour before and one hour after hemodialysis with a Spirolab III spirometer (MIR, Roma, Italy). All the spirometry tests were performed by the same technician. The calculated parameters included vital capacity (VC), forced vital capacity (FVC), forced expiratory volume in the first second (FEV1), FEV1/FVC, peak expiratory flow (PEF), and forced expiratory flow between 25\% and 75\% FVC (FEF 25\% - 75\%).

Data analysis was carried out using SPSS (Statistical Package for the Social Sciences, version 18, SPSS Inc. Chicago, IL). A paired $t$-test was used to compare the spirometry parameters before and after hemodialysis. $\mathrm{P}$ value of less than 0.05 was considered statistically significant.

\section{Results}

A total number of 50 ESRD patients (30 men and 20 women) were evaluated. The mean age was $42.40 \pm 13.52$ for men and $43.05 \pm 14.27$ for women, respectively. Baseline data of the patients are presented in Table 1, which means of age and BMI were not significantly different between men and women.

A comparison of PFT before and after hemodialysis is summarized in Table 2. Regardless of gender, comparing post-dialysis PFT parameters to pre-dialysis showed that the means of FVC and FEV1 significantly increased ( $\mathrm{P}=$ $0.021, \mathrm{P}=0.037$ respectively), the means of FEF $25 \%-75 \%$ and FEV1/FVC significantly decreased $(\mathrm{P}=0.027, \mathrm{P}=0.012$ respectively), while PEF and VC did not show significant differences.

Tables 3 and 4 display the PFT changes after HD in comparison to before HD according to gender. The table shows significant changes in FVC, FEV1 and FEV1/FVC $(\mathrm{P}=0.027, \mathrm{P}=$ 0.003 , and $\mathrm{P}=0.038$ respectively) only in men. Data shows no relationship between PFT changes and BMI, solid weight change, or ultrafiltration volume.

\section{Discussion}

CKD occurring due to diabetes, hypertension, obesity, and aging is a worldwide health problem. It can lead to ESRD, increased morbidity and mortality, and decreased quality of life. Almost all systems of the body are adversely affected by ESRD, such as respiratory, cardiovascular, and metabolic systems. The respiratory system is affected by ESRD complications and hemodialysis treatment (5).

The results of this study suggest that hemodialysis did not significantly change spirometry parameters in women, while it significantly increased FEV1 and FVC and decreased FEV1/FVC in men.

CKD, which can lead to ESRD, is a general health problem all over the world and impairs the quality of life and mortality. Unfortunately, the prevalence of ESRD is rising along with the increase in diabetes, hypertension, and 


\begin{tabular}{|c|c|c|c|c|c|c|c|c|c|}
\hline \multirow[t]{2}{*}{ Gender } & \multirow[t]{2}{*}{ Number } & \multicolumn{4}{|c|}{ Age } & \multicolumn{4}{|c|}{ BMI } \\
\hline & & Mean \pm SD & Min & Max & PValue & Mean \pm SD & Min & Max & PValue \\
\hline Male & 30 & $42.40 \pm 13.53$ & 20 & 69 & 0.781 & $21.65 \pm 3.12$ & 16.11 & 28.07 & 0.271 \\
\hline Female & 20 & $43.05 \pm 14.27$ & 23 & 78 & & $23.02 \pm 5.12$ & 17.48 & 39.06 & \\
\hline
\end{tabular}

\begin{tabular}{|c|c|c|c|c|c|c|}
\hline \multirow{2}{*}{ Parameter } & \multicolumn{2}{|c|}{ Values } & \multirow{2}{*}{ Mean Difference } & \multicolumn{2}{|c|}{ 95\% Confidence Interval of Differences } & \multirow{2}{*}{ P Value } \\
\hline & Before HD & After HD & & Lower & Upper & \\
\hline FEV1 & $2.093 \pm 0.658$ & $2.210 \pm 0.704$ & 0.116 & 0.007 & 0.226 & 0.037 \\
\hline FVC & $2.362 \pm 0.821$ & $2.551 \pm 0.968$ & 0.189 & 0.030 & 0.348 & 0.021 \\
\hline VC & $3.736 \pm 0.530$ & $3.642 \pm 0.725$ & -0.093 & -0.216 & 0.029 & 0.132 \\
\hline FEV1/FVC & $88.760 \pm 10.823$ & $85.278 \pm 12.934$ & -3.482 & -6.148 & -0.815 & 0.012 \\
\hline PEF & $4.586 \pm 1.740$ & $4.691 \pm 1.802$ & 0.104 & -0.330 & 0.539 & 0.631 \\
\hline FEF 25\% - 75\% & $2.802 \pm 1.154$ & $2.596 \pm 1.081$ & -0.206 & -0.388 & -0.024 & 0.027 \\
\hline
\end{tabular}

Abbreviations: FEF, forced expiratory flow; FEV1, forced expiratory volume in first second; FVC, forced vital capacity; PEF, peak expiratory flow; VC, vital capacity.

${ }^{\mathrm{a}}$ Values are expressed as mean $\pm \mathrm{SD}$.

\begin{tabular}{|c|c|c|c|c|c|c|}
\hline \multirow{2}{*}{ Parameter } & \multicolumn{2}{|c|}{ Values } & \multirow{2}{*}{ Mean Difference } & \multicolumn{2}{|c|}{ 95\% Confidence Interval of Differences } & \multirow{2}{*}{ PValue } \\
\hline & Before HD & After HD & & Lower & Upper & \\
\hline FEV1 & $2.355 \pm 0.538$ & $2.566 \pm 0.573$ & 0.217 & 0.077 & 0.344 & 0.003 \\
\hline FVC & $2.747 \pm 0.731$ & $3.046 \pm 0.842$ & 0.298 & 0.036 & 0.560 & 0.027 \\
\hline VC & $3.795 \pm 0.544$ & $3.798 \pm 0.545$ & 0.032 & -0.034 & 0.041 & 0.836 \\
\hline FEV1/FVC & $87.082 \pm 11.440$ & $82.928 \pm 12.564$ & -4.153 & -8.061 & -0.245 & 0.038 \\
\hline PEF & $5.266 \pm 1.718$ & $4.390 \pm 1.771$ & 0.123 & -0.604 & 0.852 & 0.730 \\
\hline FEF 25\% - 75\% & $3.107 \pm 1.314$ & $2.878 \pm 1.237$ & -0.229 & -0.508 & -0.049 & 0.103 \\
\hline
\end{tabular}

Abbreviations: FEF, forced expiratory flow; FEV1, forced expiratory volume in first second; FVC, forced vital capacity; PEF, peak expiratory flow; VC, vital capacity.

${ }^{\mathrm{a}}$ Values are expressed as mean $\pm \mathrm{SD}$.

\begin{tabular}{|c|c|c|c|c|c|c|}
\hline \multirow{2}{*}{ Parameter } & \multicolumn{2}{|c|}{ Values } & \multirow{2}{*}{ Mean Difference } & \multicolumn{2}{|c|}{ 95\% Confidence Interval of Differences } & \multirow{2}{*}{ P Value } \\
\hline & Before HD & After HD & & Lower & Upper & \\
\hline FEV1 & $1.761 \pm 0.656$ & $1.757 \pm 0.593$ & -0.003 & 0.177 & -0.184 & 0.967 \\
\hline FVC & $1.872 \pm 0.662$ & $1.922 \pm 0.732$ & 0.050 & 0.196 & -0.095 & 0.482 \\
\hline vC & $3.660 \pm 0.513$ & $3.443 \pm 0.879$ & -0.217 & 0.062 & -0.496 & 0.121 \\
\hline FEV1/FVC & $90.895 \pm 9.824$ & $88.268 \pm 13.064$ & -2.627 & 1.171 & -6.426 & 0.165 \\
\hline PEF & $3.722 \pm 1.369$ & $3.802 \pm 1.436$ & 0.080 & 0.509 & -0.348 & 0.700 \\
\hline FEF 25\% - 75\% & $2.414 \pm 0.777$ & $2.237 \pm 0.719$ & -0.176 & 0.060 & -0.414 & 0.136 \\
\hline
\end{tabular}

Abbreviations: FEF, forced expiratory flow; FEV1, forced expiratory volume in first second; FVC, forced vital capacity; PEF, peak expiratory flow; VC, vital capacity.

${ }^{\mathrm{a}}$ Values are expressed as mean $\pm \mathrm{SD}$.

obesity (21). In ESRD patients, all the body systems are affected, and they suffer from serious respiratory, coronary, and metabolic complications $(5,9)$.
The male to female ratio in our study was $60 \%$, which may be related to the higher prevalence of CKD among men or the lack of treatment due to costliness for females 
due to social, cultural, and economic limitations.

As mentioned in the results, the pulmonary function of men significantly improved after hemodialysis compared to before hemodialysis, according to FEV1 and FEC spirometry parameters. Our results on FVC were similar to those of Sharma in 2017 (9) and several other studies (5, 15, 22, 23). FVC increased similar to Rahgoshai et al.'s study (14), but FEV1 increased in the present study, which was not the case in that study. Decreased FVC, restrictive pattern, and decreased airflow in spirometry have been observed in some studies, which can be justified by acute clinical pulmonary edema resulted from increased capillary permeability and hypoalbuminemia (24). Considering the results of FEV1/FVC and FEV1 changes in this study, it was shown that large airways have not been affected by the acute renal failure condition, and the reduction in FEV1 was mainly due to the FVC decrease and restrictive lung disease. Lang et al. (25) in Munich University in Germany in 2006 examined the early effects of hemodialysis on the pulmonary function of 14 patients with ESRD, and unlike our study, they concluded that regardless of the type of used membrane, hemodialysis did not have an early impact on the pulmonary function of uremic patients.

The mean FEV1/FVC had a significant decrease after dialysis in men; however, this difference was not significant for women in this study. Having no significant change in FEV1/FVC for the women after dialysis is justified with the lack of any significant changes in their FEV1/FVC parameters that was similar to Sharma et al.'s study (9). Differences in VC, PEF, and FEF parameters were not significant for all the patients (both men and women) after dialysis compared to before. Rahgoshai et al. (14) similarly examined the short-term effects of dialysis on the respiratory function of 26 patients in Imam Hussein Hospital in Tehran in 2006 and concluded that FVC increased greatly immediately after dialysis, while no obvious improvement happened for VC, FEV1/FVC, and FEV1. The significant increase in FVC after dialysis in our study and the lack of a relationship between spirometry parameters and BMI are similar to the findings of the mentioned study.

Plesner et al. (26) examined changes in spirometry parameters in COPD patients undergoing dialysis in 2016 and found that improvement in the FEV1/FVC ratio and FEV1 was significantly related to patients' ultra-filtrated volume; furthermore, when this volume was more than 0.3 of the body weight, a significant improvement in the FEV1/FVC ratio and FEV1 was seen. This is while in our study, there was no relationship between ultra-filtrated volume and spirometry parameters.

Our results are consistent with the findings of some studies and contradictory to others. Moreover, the results of some studies have not been exactly the same as our re- sults. Differences in hemodialysis methods, dialysis duration, membrane type, disease severity, underlying diseases, and even inclusion criteria may be the reasons for this discrepancy. The small sample size in many studies was a limitation to the generalizability of the results.

\subsection{Conclusions}

In patients with ESRD on maintenance intermittent hemodialysis, hemodialysis may improve pulmonary function tests in men. More larger studies are required to better understand the valid effect of hemodialysis on spirometry parameters.

\section{Footnotes}

Authors' Contribution: Mohammad Kazem Momeni was main conductor. Narjes Sargolzai did re-evaluator of end results and analysis. Elham Shahraki was main author and main conductor. Ali Alidadi was assistant conductor. Farhad Yarmohammadi was data collector.

Conflict of Interests: It is not declared by the authors.

Ethical Approval: The ethical approval code was IR.ZAUMS.REC.1395.288.

Funding/Support: Zahedan University of Medical Sciences funded this research.

\section{References}

1. Agarwal SK, Srivastava RK. Chronic kidney disease in India: challenges and solutions. Nephron Clin Pract. 2009;111(3):5. doi: 10.1111/hdi.12342. [PubMed: 19194110].

2. Dare AJ, Fu SH, Patra J, Rodriguez PS, Thakur JS, Jha P. Renal failure deaths and their risk factors in India 2001\&\#x2013;13: nationally representative estimates from the Million Death Study. The Lancet Global Health. 2001;5(1):e89-95. doi: 10.1016/s2214-109x(16)30308-4.

3. Collins AJ, Foley RN, Gilbertson DT, Chen S. United States Renal Data System public health surveillance of chronic kidney disease and endstage renal disease. Kidney International Supplements. 2015;5(1):2-7. doi: 10.1038/kisup.2015.2. [PubMed: 26097778].

4. Mills KT, Xu Y, Zhang W, Bundy JD, Chen CS, Kelly TN, et al. A systematic analysis of worldwide population-based data on the global burden of chronic kidney disease in 2010. Kidney Int. 2015;88(5):950-7. [PubMed: 26221752].

5. Yilmaz S, Yildirim Y, Yilmaz Z, Kara AV, Taylan M, Demir M, et al. Pulmonary Function in Patients with End-Stage Renal Disease: Effects of Hemodialysis and Fluid Overload. Medical Science Monitor : International Medical Journal of Experimental and Clinical Research. 2016;22:2779-84. doi: 10.12659/msm.897480. [PubMed: 27497672].

6. Patricia A, Augustine M.Diagnosis of Respiratory Disorders. 2. Mc Graww Hill education; 2015.

7. Yong DS, Kwok AO, Wong DM, Suen MH, Chen WT, Tse DM. Symptom burden and quality of life in end-stage renal disease: a study of 179 patients on dialysis and palliative care. Palliat Med. 2009;23(2):111-9. [PubMed: 19153131].

8. Janssen DJ, Spruit MA, Wouters EF, Schols JM. Daily symptom burden in end-stage chronic organ failure: a systematic review. Palliat Med. 2008;22(8):938-48. [PubMed: 18801874]. 
9. Sharma A, Gahlot S, Prasher PK. A study of pulmonary function in endstage renal disease patients on hemodialysis: a cross-sectional study. Sao Paulo Med J. 2017;135(6):568-72. [PubMed: 29267516].

10. Farshidi H, Pour-Reza-Gholi F; Navari. Spirometry parameters in patients undergoing hemodialysis with bicarbonate and acetate dialysates. Iranian journal of kidney diseases. 2008;2(3):149-53.

11. Abdalla ME, AbdElgawad M, Alnahal A. Evaluation of pulmonary function in renal transplant recipients and chronic renal failure patients undergoing maintenance hemodialysis. Egyptian Journal of Chest Diseases and Tuberculosis. 2013;62(1):145-50. doi: 10.1016/j.ejcdt.2013.04.012.

12. Safa J, Noshad H, Ansarin K, Nikzad A, Saleh P, Ranjbar A. Ef fect of hemodialysis on pulmonary function tests and plasma endothelin levels. Saudi Journal of Kidney Diseases and Transplantation. 2014;25(4):781-7. doi: 10.4103/1319-2442.135003. [PubMed: 24969188].

13. Mukai H, Ming P, Lindholm B, Heimburger O, Barany P, Anderstam B, et al. Restrictive lung disorder is common in patients with kidney failure and associates with protein-energy wasting, inflammation and cardiovascular disease. PLoS One. 2018;13(4). [PubMed: 29702682].

14. Rahgoshai R, rahgoshai R, Nasiri AA, Solouki M; Khosraviani. Acute Effects of Hemodialysis on Pulmonary Function in Patients With Endstage Renal Disease. Iranian Journal of Kidney Diseases. 2010;4(3):214-7.

15. Karacan O, Tutal E, Uyar M, Eyuboglu FO, Sezer S, Ozdemir FN. Pulmonary function in uremic patients on long-term hemodialysis. Ren Fail. 2004;26(3):273-8. [PubMed: 15354977].

16. Ricci Z, Ronco C. Pulmonary/renal interaction. Curr Opin Crit Care 2010;16(1):13-8. doi: 10.1097/MCC.ob013e328334b13b. [PubMed 19935063].

17. Rezaeetalab F, Zeraati A, Fadaeian AH, Akbarirad M, Azami G, Shahrzad MohamadZadeh Lari S, et al. Spirometric parameters: Hemodialysis compared to peritoneal dialysis. J Cardio Thorac Med. 2015;3(2):293-6.

18. Douglas C, Murtagh FE, Chambers EJ, Howse M, Ellershaw J. Symptom management for the adult patient dying with advanced chronic kid- ney disease: a review of the literature and development of evidencebased guidelines by a United Kingdom Expert Consensus Group. Palliat Med. 2009;23(2):103-10. doi: 10.1177/0269216308100247. [PubMed: 19273566].

19. Rolla G, Bruno M, Bommarito L, Heffler E, Ferrero N, Petrarulo M, et al. Breath analysis in patients with end-stage renal disease: effect of haemodialysis. Eur J Clin Invest. 2008;38(10):728-33. doi: 10.1111/j.13652362.2008.02016.x. [PubMed: 18837798].

20. Vaziri ND, Toohey J, Paule P, Alikhani S, Hung E. Effectof hemodialysis on contact group of coagulation factors,platelets, and leukocytes. Am J Med. 1984;77:437-41.

21. Stevens LA, Viswanathan G, Weiner DE. Chronic kidney disease and end-stage renal disease in the elderly population: current prevalence, future projections, and clinical significance. Adv Chronic Kidney Dis. 2010;17(4):293-301. [PubMed: 20610356].

22. Mahmoud BL, Abdulkader A, El-Sharkawy MMS, Khalil HHM. Assessment of pulmonary functions in chronic renal failure patients with different haemodialysis regimens. Journal of the Egyptian Society of Parasitology. 2004;34(3):1025-40.

23. Kovacević P, Stanetic M, Rajkovaca Z, Meyer FJ, Vukoja M. Changes in spirometry over time in uremic patients receiving long-term hemodialysis therapy. Pneumologia. 2011;60:36-9.

24. Prezant DJ. Effect of uremia and its treatment on pulmonary function. Lung. 1990;168(1):1-14. [PubMed: 2105408].

25. Lang SM, Becker A, Fischer R, Huber RM, Schiffl H. Acute effects of hemodialysis on lung function in patients with end-stage renal disease. Wiener klinische Wochenschrift. 2006;118(3):108-13. doi: 10.1007/s00508-006-0564-7. [PubMed: 16703255].

26. Plesner LL, Warming PE, Nielsen TL, Dalsgaard M, Schou M, Høst $\mathrm{U}$, et al. Chronic obstructive pulmonary disease in patients with end-stage kidney disease on hemodialysis. Hemodialysis International. 2016;20(1):68-77. doi: 10.1111/hdi.12342. [PubMed: 26245152]. 